\title{
Parasitic Contamination of Fruits and Vegetables Collected from Local Markets of Bahir Dar City, Northwest Ethiopia
}

This article was published in the following Dove Press journal: Research and Reports in Tropical Medicine

\author{
Getaneh Alemu (D) \\ Mezgebu Nega ${ }^{2}$ \\ Megbaru Alemu (1D) \\ 'Department of Medical Laboratory \\ Science, Bahir Dar University, Bahir Dar, \\ Ethiopia; ${ }^{2}$ Department of Medical \\ Parasitology, Felegehiwot Comprehensive \\ Specialized Hospital, Bahir Dar, Ethiopia
}

Correspondence: Getaneh Alem Tel +25 1922842776

Email getanehmlt@gmail.com
Background: Fruits and vegetables, which are consumed raw, act as potential sources for the spread of various parasitic diseases. The rate of contamination and species of contaminant parasites varies based on climatic, ecological, and human factors. Therefore, local data about the contamination status and predisposing factors augments efforts for successful control of parasitic diseases.

Methods: A cross-sectional study was conducted on fruits and vegetables collected from local markets of Bahir Dar city from February to May 2019. A total of 384 samples were purchased from three randomly selected markets. Data on sociodemographic characteristics of vendors and factors associated with contamination of fruits and vegetables were collected using a structured questionnaire. About $200 \mathrm{~g}$ of fruit and vegetable samples were processed for parasites using direct wet mount and modified Zeihl-Neelson staining techniques following standard protocols. All data were analyzed using SPSS version 23.

Results: Among a total of 384 fruit and vegetable samples purchased from 112 vendors, 150 $(39.1 \%)$ were contaminated with at least one species of parasite. Lettuce $(56.4 \%)$ and mango (16.7\%) were the most and the least commonly contaminated items respectively. Larva of Strongyloides species (13.5\%) was the most frequently detected parasite followed by cysts of Entamoeba histolytica/E. dispar (12.8\%). Contamination was more common in vegetables than fruits $(\mathrm{AOR}=2.968, p<0.001)$. Fruits and vegetables purchased from vendors with untrimmed fingernails $(\mathrm{AOR}=1.966, \quad p=0.006)$, directly delivered from farmers $(\mathrm{AOR}=1.883, p=0.040)$, displayed in bucket with water $(\mathrm{AOR}=2.676, p=0.017)$ and those displayed without washing $(\mathrm{AOR}=5.511, p<0.001)$ were significantly associated with parasitic contamination.

Conclusion: The level of parasitic contamination of fruits and vegetables in Bahir Dar city is of public health importance. Hence, the public health sector should create public awareness in order to reduce parasitic transmission via fruits and vegetables.

Keywords: fruits, vegetables, contamination, parasite, market, Bahir Dar

\section{Background}

Intestinal parasites (IPs) cause morbidity and mortality throughout the world especially in developing countries. ${ }^{1}$ Globally, about 3.5 billion people are affected; 450 million are becoming sick and 200 thousand die annually from intestinal parasitic infections (IPIs). ${ }^{2,3}$ In resource-limited countries, nearly 300 million people suffer from severe morbidity. ${ }^{4,5}$ In Ethiopia, as in other Sub-Saharan African countries, parasitic infections (PIs) are widely distributed and affect various segments of the population. ${ }^{6}$ Intestinal parasites are the second most common cause of 
outpatient morbidity in the country. ${ }^{7}$ They are known to cause diarrhea, anemia, stunting, physical weakness, low educational performance, growth retardation in children, and other physical and mental health problems. ${ }^{5}$

Intestinal parasites are primarily transmitted by fecal-oral route, mostly via ingestion with contaminated food and water or during direct hand to mouth contact. ${ }^{8,9}$ Food items which are usually consumed raw, like fruits and vegetables, are potential sources of infection. In most cases, fruits and vegetables are eaten raw or lightly cooked in order to retain the natural taste and to preserve heat labile nutrients. This practice, however, facilitates the transmission of food-borne infections. ${ }^{1,10-12}$ Studies conducted on various items of fruit and vegetable samples have shown that Ascaris lumbricoides, Cryptosporidium spp, Entamoeba histolytica, Enterobius vermicularis, Fasciola spp, Giardia lamblia, hookworms, Hymenolepis spp, Taenia spp, Trichuris trichiura, Cyclospora spp, and Toxocara spp infect humans who consume contaminated fruits and vegetables without cooking or washing them properly. ${ }^{1,4,13-16}$ Epidemiological studies indicated that the number of reported cases of foodborne illnesses due to consumption of raw fruits and vegetables has been increasing and continues to be a common and serious threat to public health in endemic areas for IPs. ${ }^{10,15,17}$

Fruits and vegetables can become contaminated with parasitic pathogens throughout the process from planting to consumption. ${ }^{18}$ Use of human and animal excreta as natural fertilizer, and untreated waste water for irrigation during cultivation are the main contributing factors in the preharvesting phase. In developing countries, majority local farmers use untreated human or animal dung as fertilizer and polluted or untreated water for irrigation which contributes for increased transmission of IPs. ${ }^{19}$ Factors in the post-harvesting phase include storage, transportation and marketing conditions as well as hygienic practice during processing for consumption in food service or home settings. ${ }^{12,20}$

Ethiopia is a country where many of IPs are abundant. There is also poor water supply, hygiene and sanitary practice. Hence, it is expected that farmlands will be contaminated with infective IPs mainly due to open defecation. In addition, natural fertilizer (human and animal excreta) is commonly used by farmers in the country and water used for irrigation is usually contaminated. ${ }^{15}$ Moreover, fruits and vegetables such as banana, mango, tomato, salad, and green pepper are frequently consumed raw. All these contribute to parasitic contamination of fruits and vegetables so that these food items serve as important vehicles for transmission in humans. ${ }^{21}$ Recent studies in Ethiopia showed that $25.1 \%$ to $57.8 \%$ of the fruit and vegetable samples collected at the marketing phase were contaminated with parasites. ${ }^{5,15,21,22}$ However, the rate of contamination and species of parasites vary by weather conditions, sociocultural status, season of sample collection, fruit and vegetable items examined and other factors. This demands monitoring of the contamination status and contributing factors at local settings in order to intervene in transmission of IPs. Despite this, there is no adequate data in and around Bahir Dar city. Hence, the aim of the present study was to assess parasitic contamination rate of fruits and vegetables and associated factors in selected local markets of Bahir Dar city where it is common to see fruits and vegetables being sold in open markets and streets, and where people are consuming those fruits and vegetables raw.

\section{Methods}

\section{Study Design, Area and Period}

A cross-sectional study was conducted in selected local markets of Bahir Dar city from February to May 2019. Bahir Dar is the capital city of Amhara National Regional State which is located $565 \mathrm{~km}$ Northwest of Addis Ababa, the capital of Ethiopia. ${ }^{23}$ Bahir Dar is located at $11^{\circ} 36^{\prime \prime}$ north latitude and $37^{\circ} 23^{\prime}$ " east longitude on the shore of Lake Tana and Blue Nile and at an elevation of 1799 meters above sea level. ${ }^{24}$ The major economic sectors of the city are horticulture, agro-industrial processing, urban agriculture, manufacturing, and diverse service industries. ${ }^{23}$ The weather condition in and around the city is conducive for cultivation of diverse items of fruits and vegetables. Those fruits and vegetables are readily available in local markets throughout the town and most items are eaten raw. Abay ena tana, Abay mado, Amedo, Kidanemihiret, Kuchit lelimat, Gofa mazoria and Silase are local markets where the majority of fruits and vegetables are brought directly from farmers or middlemen in order to sell to consumers. Data for the present study was collected from three randomly selected markets namely, Abay ena tana, Abay mado and Gofa mazoria.

\section{Data Collection and Screening for Parasite Contamination}

A structured questionnaire was used to collect data on sociodemographic characteristics of vendors as well as environmental and health-related factors through a face to face interview and observation. Approximately equal 
numbers of fruit and vegetable samples (55) of lettuce (Lactuca serriola), spinach (Spinacea oleracea), cabbage (Brassica oleracea), carrot (Daucus carota), tomato (Lycopersicon esculentum), mango (Mangifera indica) and green pepper (Capsicum annuиm) were purchased from local markets. The samples were collected once only in each market until 55 of each vegetable and/or fruit were collected. Collected fruits and vegetables were collected, put in sterile plastic bags, properly labeled, and transported in a cold box to the Microbiology and Parasitology Teaching Laboratory of College of Medicine and Health Sciences at Bahir Dar University for parasitological examination. Approximately $200 \mathrm{~g}$ of each fruit and vegetable sample were chopped using sterile knife and chopping pad, soaked and rinsed in a beaker containing $500 \mathrm{~mL}$ of normal saline $(0.85 \% \mathrm{NaCl})$ for $20 \mathrm{~min}$ followed by agitation in a shaker for $5 \mathrm{~min}$ to facilitate adequate washing. ${ }^{22,25} \mathrm{Then}$, samples were removed from the beaker and the washing solution was incubated overnight for adequate sedimentation of parasite stages. About $15 \mathrm{~mL}$ of the sediment was transferred to a centrifuge tube using a sieve to remove undesirable matter. For adequate concentration of the parasitic stages, the content was centrifuged at 3000 revolutions per minute for $5 \mathrm{~min}$. Then, the supernatant was decanted carefully without shaking and the sediment was agitated gently by hand to resuspend the sediment. Part of the sediment was used for direct and iodine wet mount smear preparation and examined under light microscope using $10 \dot{x}$ and $40 \dot{x}$ objectives for the detection of parasite ova, larvae, and cysts. The remaining sediment was processed and examined by Modified Ziehl-Neelsen staining technique for the detection of coccidian oocysts following standard protocol explained elsewhere. ${ }^{21,26}$ Two slides were prepared and examined per sample in both the direct wet mount and Modified Ziehl-Neelsen staining techniques.

\section{Statistical Analysis}

Data were analyzed using SPSS version 23 (IBM Corporation, Armonk, NY, USA). Descriptive statistics like frequency and proportion were calculated to explain characteristics of vendors and contamination status of fruits and vegetables. Binary logistic regression analysis was done to assess factors associated with fruit and vegetable contamination. Variables with $p$-value $<0.25$ in the binary logistic regression analysis were taken as candidates for multiple logistic regression in order to avoid the effect of confounders. ${ }^{22}$ An association with $p$-value $<0.05$ at $95 \% \mathrm{CI}$ was considered as significant.

\section{Ethics Approval and Consent to Participate}

An ethical approval letter was obtained from Bahir Dar University Research and Ethical Review Committee. An official permission letter was obtained from Bahir Dar zonal health department, Bahir Dar Zonal police department and zonal trade department. Verbal informed consent was obtained from each study participants (vendor). Verbal informed consent was acceptable and approved by the Bahir Dar University, College of Medicine and Health Sciences Research and Ethical Review Committee.

\section{Results}

\section{Parasitic Contamination Rate of Fruits and Vegetables}

A total of 384 fruit and vegetable samples were collected from 112 vendors. Twenty-four of the vendors $(21.4 \%)$ were male and $88(78.6 \%)$ were female. Of the vendors interviewed, 47, 36, and 29 were from Abay ena Tana, Abay Mado, and Gofa Mazoria, respectively. On average each vendor displayed three items of fruits and/or vegetables for selling. Majority of them have attended at least primary school and only 17 (15.2\%) were unable to read and write. Sixty-seven vendors trimmed their fingernails well, while 45 were observed to have untrimmed fingernails. Among a total of 384 (164 fruit and 220 vegetable) samples examined, 150 (39.1\%; 95\%CI: 34.1-44.0) were contaminated with at least a single parasite species. Contamination rate of fruits alone was $25.6 \%$ while that of vegetables was $49.1 \%$. Out of 150 contaminated samples, 119 (79.3\%) and 25 (16.7\%) were contaminated with one and two parasite species, respectively. Contamination with multiple parasitic species was more commonly observed in vegetables $(12.3 \%)$ than in fruits (2.4\%). Among vegetables, lettuce $(56.4 \%)$ was the most frequently contaminated item followed by spinach (52.7\%). Regarding fruits, tomato (30.9\%) and green pepper (29.1\%) have almost similar rates of contamination while mango (16.7\%) show the least frequency of contamination (Table 1).

Both protozoa (29.4\%) and helminth (19.3\%) parasites were detected as contaminants of fruits and vegetables. Cysts of E. histolytica/E. dispar (12.8\%) were the most commonly detected protozoa followed by $G$. lamblia (10.2\%). Among helminthic parasites detected, larva of Strongyloides spp (13.5\%) was the most frequent while all other helminths show $1.8 \%$ or less distribution (Table 2). 
Table I Frequency of Distribution of Parasitic Contaminations Among Fruits and Vegetables Sold in Local Markets of Bair Dar City, Northwest Ethiopia from February to May 2019 ( $\mathrm{N}=384)$

\begin{tabular}{|c|c|c|c|c|c|c|c|}
\hline \multirow[t]{2}{*}{ Kind of Produce } & \multirow[t]{2}{*}{ Item } & \multirow[t]{2}{*}{ Number Examined } & \multirow[t]{2}{*}{ Number Positive (\%) } & \multicolumn{4}{|c|}{ Parasite Species Detected, N (\%) } \\
\hline & & & & One & Two & Three & Four \\
\hline \multirow[t]{5}{*}{ Vegetables } & Lettuce & 55 & $31(56.4)$ & $24(43.6)$ & $7(12.7)$ & 0 & 0 \\
\hline & Spinach & 55 & $29(52.7)$ & $25(45.5)$ & $3(5.5)$ & $\mathrm{I}(\mathrm{l} .8)$ & 0 \\
\hline & Carrot & 55 & $25(45.5)$ & $18(32.7)$ & $5(9.1)$ & $2(3.6)$ & 0 \\
\hline & Cabbage & 55 & $23(4 \mid .8)$ & $14(25.5)$ & $6(10.9)$ & $2(3.6)$ & I (I.8) \\
\hline & Total & 220 & $108(49.1)$ & $81(36.8)$ & $21(9.5)$ & $5(2.3)$ & I $(0.5)$ \\
\hline \multirow[t]{4}{*}{ Fruits } & Tomato & 55 & $17(30.9)$ & $15(27.3)$ & $2(3.6)$ & 0 & 0 \\
\hline & Green Pepper & 55 & $16(29.1)$ & $14(25.5)$ & $2(3.6)$ & 0 & 0 \\
\hline & Mango & 54 & $9(16.7)$ & $9(16.7)$ & 0 & 0 & 0 \\
\hline & Total & 164 & $42(25.6)$ & $38(23.2)$ & $4(2.4)$ & 0 & 0 \\
\hline \multicolumn{2}{|l|}{ Overall distribution } & 384 & $150(39.1)$ & $119(31)$ & $25(6.5)$ & $5(1.3)$ & I $(0.3)$ \\
\hline
\end{tabular}

Table 2 Frequency of Detected Parasites Depending on Type of Produces Sold at Local Markets of Bair Dar City, Northwest Ethiopia from February to May $2019(\mathrm{~N}=384)$

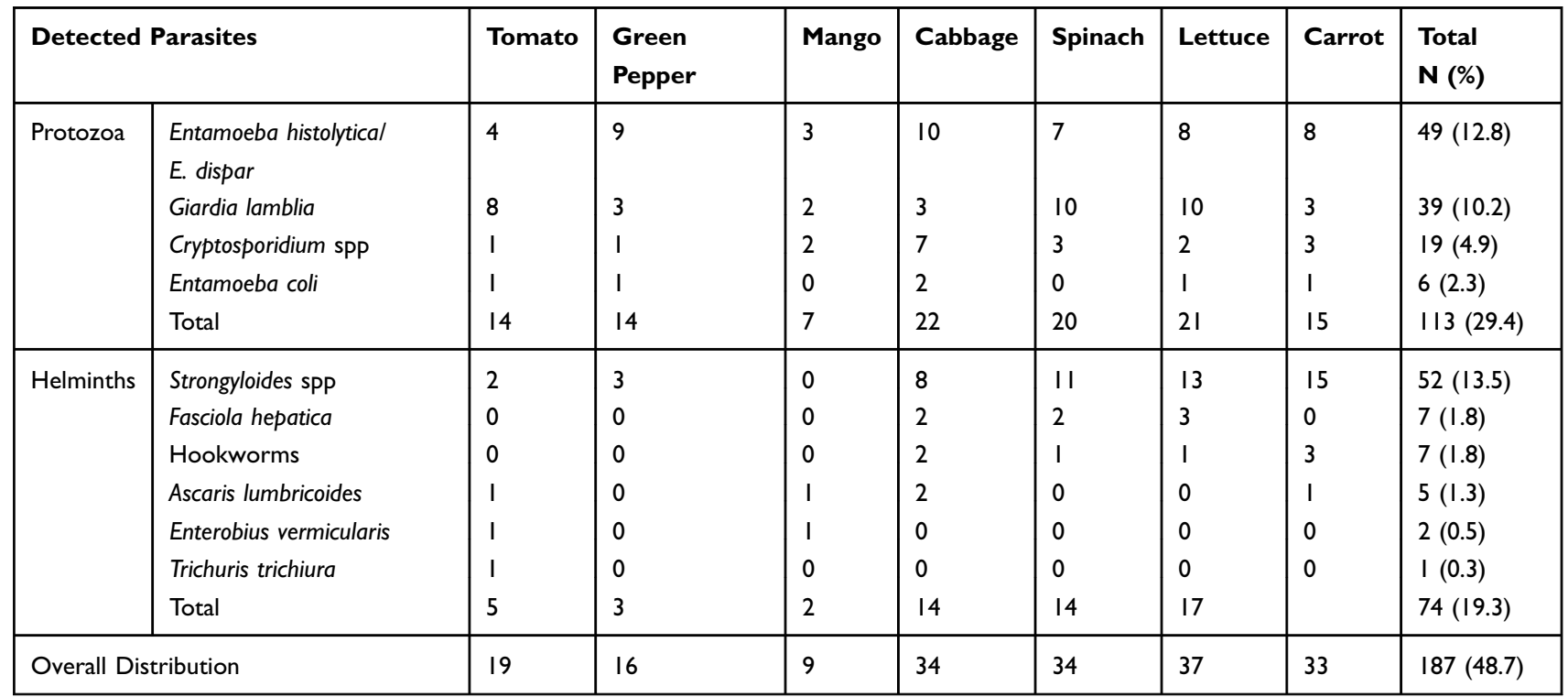

Abbreviation: spp, species.

\section{Factors Associated with Parasitic}

\section{Contamination of Fruits and Vegetables}

Fruits and vegetables sold by vendors who were unable to read and write (53.4\%) and attended primary school (41.4\%) had a higher contamination rate compared to those sold by vendors who have attended secondary school or above (31.7\%); however, the difference in contamination rate was not statistically significant $(p>0.05)$. Finger nail status of vendors was significantly associated with parasitic contamination. Consequently, fruits and vegetables sold by vendors with untrimmed fingernails were twice (AOR $=1.966 ; 95 \%$ CI: $1.210-3.193, p=0.006$ ) as likely to be contaminated compared to those sold by vendors with trimmed fingernails.
Binary logistic regression also showed that vegetables were at higher risk of being contaminated compared to fruits (AOR $=2.968 ; 95 \%$ CI: 1.702-5.176, $\mathrm{p}<0.001)$. Similarly, fruits and vegetables directly delivered from farmers (AOR $=1.883 ; 95 \%$ CI: $1.028-3.448, \quad \mathrm{p}=0.040)$, those washed before display (AOR $=5.511 ; 95 \%$ CI: 3.014-10.075, $p<0.001)$ and displayed in a bucket with water (AOR=2.676; 95\%CI: 1.191-6.012, $p=0.017$ ) were significantly associated with less parasitic contamination (Table 3 ).

\section{Discussion}

The present study, for the first time, assessed parasitic contamination status and contributing factors of fruits 
Table 3 Binary Logistic Regression Analysis of Factors Associated with Parasite Contamination of Fruits and Vegetables Sold in Local Markets of Bair Dar City, Northwest Ethiopia from February to May 2019

\begin{tabular}{|c|c|c|c|c|c|c|c|}
\hline Variables & Categories & $\begin{array}{l}\text { Number } \\
\text { Examined }\end{array}$ & $\begin{array}{l}\text { Contamination } \\
\text { Rate } \\
\text { N (\%) }\end{array}$ & COR $(95 \% \mathrm{Cl})$ & $p$-value & AOR $(95 \% \mathrm{Cl})$ & $p$-value \\
\hline Marketplace & $\begin{array}{l}\text { Abay mado } \\
\text { Abay and tana } \\
\text { Gofa mazoria }\end{array}$ & $\begin{array}{l}127 \\
147 \\
110\end{array}$ & $\begin{array}{l}51(40.2) \\
58(39.5) \\
41(37.3)\end{array}$ & $\begin{array}{l}1.129(0.668-1.908) \\
1.097(0.659-1.824) \\
1\end{array}$ & $\begin{array}{l}0.650 \\
0.722\end{array}$ & & \\
\hline Sex of vendors & $\begin{array}{l}\text { Male } \\
\text { Female }\end{array}$ & $\begin{array}{l}67 \\
317\end{array}$ & $\begin{array}{l}26(38.8) \\
124(39.1)\end{array}$ & $\begin{array}{l}1 \\
1.013(0.590-1.740)\end{array}$ & 0.962 & & \\
\hline $\begin{array}{l}\text { Educational level of } \\
\text { vendors }\end{array}$ & $\begin{array}{l}\text { Unable to read and write } \\
\text { Primary education } \\
\text { Secondary and above }\end{array}$ & $\begin{array}{l}58 \\
162 \\
164\end{array}$ & $\begin{array}{l}31(53.4) \\
67(41.4) \\
52(31.7)\end{array}$ & $\begin{array}{l}2.473(1.34 \mid-4.560) \\
1.519(0.965-2.391) \\
1\end{array}$ & $\begin{array}{l}0.004 \\
0.071\end{array}$ & $\begin{array}{l}1.734(0.813-3.696) \\
1.209(0.7 \mid 5-2.045) \\
I\end{array}$ & $\begin{array}{l}0.154 \\
0.480\end{array}$ \\
\hline $\begin{array}{l}\text { Venders' fingernail } \\
\text { status }\end{array}$ & $\begin{array}{l}\text { Trimmed } \\
\text { Untrimmed }\end{array}$ & $\begin{array}{l}229 \\
155\end{array}$ & $\begin{array}{l}71(31.0) \\
79(51.0)\end{array}$ & $\begin{array}{l}\text { I } \\
2.313(1.5 \mid 8-3.526)\end{array}$ & 0.000 & $\begin{array}{l}\text { I } \\
1.966(1.210-3.193)\end{array}$ & 0.006 \\
\hline Produce type & $\begin{array}{l}\text { Fruit } \\
\text { Vegetable }\end{array}$ & $\begin{array}{l}164 \\
220\end{array}$ & $\begin{array}{l}42(25.6) \\
108(49.1)\end{array}$ & $\begin{array}{l}\text { I } \\
2.801(1.806-4.345)\end{array}$ & 0.000 & $\begin{array}{l}\text { I } \\
2.968(1.702-5.176)\end{array}$ & 0.000 \\
\hline $\begin{array}{l}\text { Sources of } \\
\text { produce }\end{array}$ & $\begin{array}{l}\text { Farmers } \\
\text { Middle men }\end{array}$ & $\begin{array}{l}154 \\
230\end{array}$ & $\begin{array}{l}69(44.8) \\
81(35.2)\end{array}$ & $\begin{array}{l}1.493(0.984-2.266) \\
\text { I }\end{array}$ & 0.060 & $\begin{array}{l}1.883(1.028-3.448) \\
1\end{array}$ & 0.040 \\
\hline Displaying place & $\begin{array}{l}\text { Grocery } \\
\text { Open market }\end{array}$ & $\begin{array}{l}106 \\
278\end{array}$ & $\begin{array}{l}31(29.2) \\
119(42.8)\end{array}$ & $\begin{array}{l}\text { I } \\
1.811(1.119-2.930)\end{array}$ & 0.016 & $\begin{array}{l}1 \\
1.098(0.565-2.136)\end{array}$ & 0.782 \\
\hline $\begin{array}{l}\text { Washed before } \\
\text { display }\end{array}$ & $\begin{array}{l}\text { Yes } \\
\text { No }\end{array}$ & $\begin{array}{l}152 \\
232\end{array}$ & $\begin{array}{l}40(26.3) \\
110(47.4)\end{array}$ & $\begin{array}{l}\text { I } \\
2.613(1.673-4.081)\end{array}$ & 0.000 & $\begin{array}{l}\text { I } \\
5.51 I(3.014-10.075)\end{array}$ & 0.000 \\
\hline Means of display & $\begin{array}{l}\text { In a bucket with water } \\
\text { In a bucket without water } \\
\text { On the floor } \\
\text { On table/shelf }\end{array}$ & $\begin{array}{l}97 \\
17 \\
152 \\
118\end{array}$ & $\begin{array}{l}52(53.6) \\
7(41.2) \\
62(40.8) \\
29(24.6)\end{array}$ & $\begin{array}{l}3.546(1.988-6.326) \\
2.148(0.750-6.157) \\
2.114(1.245-3.590) \\
1\end{array}$ & $\begin{array}{l}0.000 \\
0.155 \\
0.006\end{array}$ & $\begin{array}{l}2.676(1.191-6.012) \\
1.536(0.453-5.209) \\
1.586(0.805-3.123) \\
1\end{array}$ & $\begin{array}{l}0.017 \\
0.491 \\
0.183\end{array}$ \\
\hline $\begin{array}{l}\text { Means of } \\
\text { transportation }\end{array}$ & $\begin{array}{l}\text { By human } \\
\text { By cart } \\
\text { By car }\end{array}$ & $\begin{array}{l}134 \\
78 \\
172\end{array}$ & $\begin{array}{l}57(42.5) \\
30(38.5) \\
63(36.6)\end{array}$ & $\begin{array}{l}\text { I.28I (0.807-2.033) } \\
\text { I.08I (0.623-1.877)T } \\
\text { I }\end{array}$ & $\begin{array}{l}0.294 \\
0.781\end{array}$ & & \\
\hline
\end{tabular}

Abbreviations: AOR, adjusted odds ratio; COR, crude odds ratio.

and vegetables at marketing phase in Bahir Dar city. The overall parasitic contamination rate (39.1\%) in the present study was in agreement with previous findings from Tarcha town of Southwest Ethiopia (39.0\%), Sharkyia governorate of Egypt (39\%), Oyo (35.4\%) and Plateau $(36.0 \%)$ States of Nigeria and Southern Thailand $(35.1 \%){ }^{27-31}$

However, the present result was lower than findings of similar studies in Brazil (50.9\%); Yemen (100\%); Cape Coast metropolis market (52.4\%), and Koforidua (57.5\%) in the Eastern Region of Ghana; Jos State in Nigeria (56.25\%); Asmara State of Eritrea (57.07\%); Dire Dawa (47.3\%), Arba Minch (54.4\%), Jimma (57.8\%) and Dessie (63.4\%) towns in Ethiopia. ${ }^{5,15,19,21,32-37}$ The difference could be due to variations in items of samples collected, processing and laboratory methods used. For example, in the study from Ghana, fruits and vegetables were thoroughly washed twice with saline in order to increase recovery of parasites $;{ }^{37}$ but in the present study, samples were washed only once. In the study from Brazil, vegetable samples (lettuce, green onion, and salad) were collected between February and July and triplicate slides were examined. ${ }^{33}$ Data for the present study was collected in the dry season when the transmission, and hence the prevalence, is relatively low. All these features contribute to a higher contamination rate than in the present study.

Time of sample collection might be another factor in that studies in Dire Dawa, Arba Minch, Jimma, and Dessie towns in Ethiopia were conducted before the launching of the national mass drug administration and 
water, sanitation and hygiene (WASH) programs in the country. Since 2015, many WASH activities, health education, and biannual deworming programs for helminths have been conducted and substantially decreased environmental fecal contamination as well as parasitic contamination. The parasitic contamination rate in Arba Minch town was reduced from $54.4 \%$ in 2014 to $25.1 \%$ in 2018 . $^{15,22}$ Variations in geographical distribution of parasites, sanitary and socioeconomic status of the community could be the other contributing factors.

Alternatively, the overall contamination rate in the present study was higher than findings in Iran (8.4\%); Ibadan city of Southwest Nigeria (11.6\%); Alexandria (31.7\%) and Benha (29.6\%) in Egypt; Sudan (10.6\%) and Arba Minch town (25.1\%). 16,17,22,38,39 Factors mentioned above could also contribute here. For instance, in the study from Egypt, samples were washed with tap water for 6-7 min for removal of mud and dust before being immersed in physiological saline. ${ }^{38}$ This could decrease as some of the parasites might be removed with mud and dust particles. A study from Sudan screened only 150 samples and non-leafy items were screened and samples were not processed by modified acid-fast staining; therefore oocysts of intestinal coccidian were not assessed; ${ }^{39}$ all contributing to a lower contamination rate compared to the present study. In a study from Arba Minch, a variable number of fruit and vegetable samples from each item were screened unlike the equal number of each item in the present study. This might bring variation in the two studies because there is a difference in susceptibility to contamination among different items of fruits and vegetables. ${ }^{15,21,22}$

In this study, lettuce was the most frequently contaminated item $(56.4 \%)$ while mango was the least contaminated $(16.7 \%)$. Vegetables are more prone to contamination than fruits due to the fact that vegetables like lettuce, spinach and cabbage have uneven/rough surfaces which enable parasites to attach more easily and overcome the effects of washing. ${ }^{25,38}$ Owing to the softness and fragility of leaves of vegetables, most vendors do not thoroughly wash them before display. ${ }^{4}$ On the contrary, the smooth surface of fruits like green pepper, tomato and mango might reduce the rate of parasitic attachment and can be washed easily. Edible parts of vegetables grow closer to the soil than that of fruits. Hence, soil may also play significant role in the contamination of vegetables. ${ }^{40,41}$ In support of this, vegetables were 3.0 times more likely to be contaminated as compared to fruits $(p<0.001)$ in the present study. Use of human and animal excreta as an organic fertilizer might contribute for this contamination as confirmed by a couple of studies in Ethiopia. ${ }^{42}$

Larva of Strongyloides spp (13.5\%) was the most frequently detected parasite. This might be due to the fact that the parasite has a free-living state making it abundant in the environment; hence easily contaminating fruits and vegetables. ${ }^{21,35}$ Besides, Strongyloides spp infecting animal reservoirs like dogs could also contaminate the environment. The predominance of Strongyloides spp was similar to findings from Ghana (43.7\%); Nigeria (60.4\%); Sudan (62.5\%); Jimma (21.9\%) and Mekelle (63. 63\%). ${ }^{19,21,35,39,42}$ However, the present finding was higher than that reported by other previous studies. $^{17,22,30,34}$

Cysts of E. histolytica/E. dispar (12.8\%) were also detected with high frequency in the present study. This finding was lower than reports from Sudan (42.9\%) and Dessie town $(24 \%)$, but higher than results from Arba Minch (8.4\%). ${ }^{22,36,43}$ Cysts of G. lamblia (10.2\%) were the third most common parasite detected in the present study. However, the prevalence was lower than the previous studies done in Asmara state of Eretria (36.4\%), Khartoum state of Sudan (22.9\%), and higher than the results of Dessie town $(1.33 \%) .{ }^{34,36,43}$ Variation in the prevalence of E. histolytica/E. dispar and G. lamblia might be attributed to the long periods of survival of the cysts under cool and moist conditions and variations in geographical distribution. ${ }^{29,33}$

According to the present study, soil-transmitted helminths (A. lumbricoides, hookworms and T. trichiura) were among the least detected parasites. But our results disagree with findings in Nigeria, Egypt, Eretria; Arba Minch and Tarcha towns in Ethiopia; where the occurrence of $A$. lumbricoides was $56.31 \%, 20.3 \%, 12.5 \%, 20.83 \%$, and $16.7 \%$, respectively. ${ }^{15,30,34,38,44}$ Similarly, in Oyo State of Nigeria, A. lumbricoides (55.9\%) and hookworms $(32.3 \%)$ were predominant. ${ }^{28}$ The difference might be due to the effect of an ongoing biannual deworming program targeting soil-transmitted helminths, improvements in WASH program activities and health education by the health workers to avoid open defecation in the environment.

Findings from multiple logistic regression analysis revealed that fruits and vegetables displayed without washing were 5.6 times more likely to be contaminated with parasites compared to those washed before display. The present findings are consistent with a study conducted in Dire Dawa, Arba Minch, and Jimma. ${ }^{5,15,21}$ Therefore, it is justifiable that washing before display removes parasites. However, the 
present finding disagrees with previous reports by Alemu et al,; Bekele and Shumbej, in Arba Minch. ${ }^{15,22}$ The cleanliness of water used for washing and the washing process might bring such discrepancies. In addition, fruits and vegetables displayed in a bucket immersed in water were 2.7 times more likely to be contaminated compared to those displayed on table/shelf, most probably, due to cross contamination during immersion.

Untrimmed fingernails collect dirt and parasite stages which, in turn, contaminate everything touched. Hence, vendors who have untrimmed fingernails were 2.1 times more likely to contaminate fruits and vegetables in the present study. Fruits and vegetables directly supplied by farmers to vendors were 2.0 times more likely to be contaminated with parasites compared to vegetables supplied from middlemen. Middlemen receive fruits and vegetables on the farmland, pack and transport to Bahir Dar city using their vehicle, store it properly and distribute to small scale vendors. Conversely, small-scale vendors who receive vegetables directly from farmers transport it either on the back of animals or via human labor, whereby, fruits and vegetables are readily exposed to contamination. In the present study, it was not possible to separately report only parasite species of human medical importance because some species are morphologically indistinguishable. Moreover, factors associated with parasitic contamination at pre and post-marketing phases were not assessed.

\section{Conclusion}

The level of parasitic contamination of fruits and vegetables in Bahir Dar city is considerable. Leafy vegetables are more prone to contamination than fruits. Strongyloides spp, E. histolytica/E. dispar and G. lamblia were the common contaminants of fruits and vegetables with comparable distribution. Fruits and vegetables sold by vendors having untrimmed fingernails, directly delivered from farmers, displayed in a bucket with water and without washing were at higher risk of parasitic contamination. Hence, the public health sector should create awareness among farmers, vendors and consumers about safe cultivation, transportation, handling and consumption of fruits and vegetables. Periodic screening of on-market fruits and vegetables should be done. Large scale studies targeting fruits and vegetables both at pre-harvest and postharvest phases using molecular detection methods are recommended to exhaustively identify sources of contamination and to detect pathogenic parasitic contaminants.

\section{Abbreviations}

AOD, adjusted odds ratio; COR, crude odds ratio; IPs, intestinal parasites; IPI, intestinal parasitic infection; WASH, water, sanitation and hygiene.

\section{Data Sharing Statement}

The original data for this study is available from the corresponding author.

\section{Acknowledgments}

The authors thank Bahir Dar University for giving ethical clearance; and Amhara Public Health Institute for supporting with laboratory materials. The authors' gratitude goes to fruit and vegetable vendors of Bahir Dar city who participated in the study.

\section{Author Contributions}

All authors contributed to data collection and analysis, drafting and revising the article, gave final approval of the version to be published, and agree to be accountable for all aspects of the work.

\section{Disclosure}

The authors report no conflicts of interest in this work.

\section{References}

1. Adejumoke A, Morenikeji O. Prevalence of intestinal parasites in vegetables sold in major markets in Ibadan city, south-west Nigeria. Glob J Pure Appl Sci. 2015;21(1):7-12.

2. Wegayehu T, Tsalla T, Seifu B, Teklu T. Prevalence of intestinal parasitic infections among highland and lowland dwellers in Gamo area, South Ethiopia. BMC Public Health. 2013;13(1). doi:10.1186/ 1471-2458-13-151

3. Stofer J. Adverse Health Effects of Intestinal Parasitic Infections in Rural Peruvian Clinic Patients. Dayton, Ohio: Wright State University; 2014. Available from: https://corescholar.libraries.wright. edu/mph. Accessed March 10, 2020.

4. Duedu K, Yarnie E, Tetteh-Quarcoo P, Attah S, Donkor E, Ayeh-Kumi P. A comparative survey of the prevalence of human parasites found in fresh vegetables sold in supermarkets and open-aired markets in Accra, Ghana. BMC Res Notes. 2014;7(1). doi:10.1186/1756-0500$7-836$

5. Endale A, Tafa B, Bekele D, Tesfaye F. Detection of medically important parasites in fruits and vegetables collected from local markets in Dire Dawa, Eastern Ethiopia. Glob J Med Res. 2018;18 (1):29-36

6. Mekonnen B, Erko B, Legesse M. Prevalence of intestinal parasitic infections and related risk factors among Street Dwellers in Addis Ababa, Ethiopia. J Trop Dis Public Health. 2014;2(2). doi:10.4172/ 2329-891X.1000132

7. Aiemjoy K, Gebresillasie S, Stoller N, et al. Epidemiology of soil-transmitted helminth and intestinal Protozoan infections in preschool-aged children in the Amhara region of Ethiopia. Am J Trop Med Hyg. 2017;96(4):866-872. doi:10.4269/ajtmh.16-0800 
8. Nazemi S, Raei M, Amiri M, Chaman R. Parasitic contamination of raw vegetables in Shahroud, Semnan. Zahedan J Res Med Sci. 2012;14(8):84-86.

9. Abdelrahim A. Role of contaminated fruits in the transmission of intestinal parasites in Khartoum Central Market-Khartoum State [Doctoral dissertation, Sudan University of Science \& Technology]; 2017. Available from: http://repository.sustech.edu/handle/ 123456789/18395. Accessed 25 August 2019.

10. Berger C, Sodha S, Shaw R, et al. Fresh fruit and vegetables as vehicles for the transmission of human pathogens. Environ Microbiol. 2010;12 (9):2385-2397. doi:10.1111/j.1462-2920.2010.02297.x

11. Slavin J, Lloyd B. Health benefits of fruits and vegetables. Adv Nutr. 2012;3(4):506-516. doi:10.3945/an.112.002154

12. Alhabbal A. The prevalence of parasitic contamination on common cold vegetables in Alqalamoun Region. Int J Pharm Sci Rev Res. 2015;30(1):94-97.

13. Fallah A, Pirali-Kheirabadi K, Shirvani F, Saei-Dehkordi S. Prevalence of parasitic contamination in vegetables used for raw consumption in Shahrekord, Iran: influence of season and washing procedure. Food Control. 2012;25(2):617-620. doi:10.1016/j. foodcont.2011.12.004

14. Siyadatpanah A, Tabatabaei F, Zeydi A, et al. Parasitic contamination of raw vegetables in Amol, North of Iran. Arch Clin Infect Dis. 2013;8(2). doi:10.5812/archcid.15983

15. Bekele F, Tefera T, Biresaw G, Yohannes T. Parasitic contamination of raw vegetables and fruits collected from selected local markets in Arba Minch town, Southern Ethiopia. Infect Dis Poverty. 2017;6(1). doi:10.1186/s40249-016-0226-6

16. Matini M, Shamsi-Ehsan T, Maghsood H. The parasitic contamination of farm vegetables in Asadabad City, West of Iran, in 2014. Avicenna J Clin Microbiol Infect. 2017;4(1). doi:10.5812/ajcmi.42380

17. Eraky M, Rashed S, Nasr M, El-Hamshary A, Salah El-Ghannam A. Parasitic contamination of commonly consumed fresh leafy vegetables in Benha, Egypt. J Parasitol Res. 2014;7. doi:10.1155/2014/613960.

18. Adenusi A, Abimbola W, Adewoga T. Human intestinal helminth contamination in pre-washed, fresh vegetables for sale in major markets in Ogun State, southwest Nigeria. Food Control. 2015;50:843-849. doi:10.1016/j.foodcont.2014.10.033

19. Idahosa O. Parasitic contamination of fresh vegetables sold in Jos markets. Glob J Med Res. 2011;11(1):21-25.

20. Amoah P, Drechsel P, Abaidoo R, Klutse A. Effectiveness of common and improved sanitary washing methods in selected cities of West Africa for the reduction of coliform bacteria and helminth eggs on vegetables. Trop Med Int Health. 2007;12:40-50. doi:10.1111/ j.1365-3156.2007.01940.x

21. Tefera T, Biruksew A, Mekonnen Z, Eshetu T. Parasitic contamination of fruits and vegetables collected from selected local markets of Jimma town, southwest Ethiopia. Int Scholarly Res Not. 2014;7. doi:10.1155/2014/382715

22. Alemu G, Mama M, Misker D, Haftu D. Parasitic contamination of vegetables marketed in Arba Minch town, southern Ethiopia. BMC Infect Dis. 2019;19(1):410. doi:10.1186/s12879-019-4020-5

23. Valdés-Cotera R, Longworth N, Lunardon K, Wang M, Crowe S. Unlocking the Potential of Urban Communities: Case Studies of Twelve Learning Cities. Feldbrunnenstrasse 58, 20148 Hamburg, Germany: UNESCO Institute for Lifelong Learning; 2015. ISBN: 978-92-820-1195-9.

24. Birara E, Kassahun T. Assessment of solid waste management practices in Bahir Dar City, Ethiopia. Pollution. 2018;4(2):251-261.

25. Ismail Y. Prevalence of parasitic contamination in salad vegetables collected from supermarkets and street vendors in Amman and Baqa'a-Jordan. Polish J Microbiol. 2016;65(2):201-207. doi:10. 33073/pjm-

26. Ebrahimzadeh A, Jamshidi A, Mohammadi S. The parasitic contamination of raw vegetables consumed in Zahedan, Iran. Health Scope. 2013;1(4):205-209. doi:10.17795/jhs
27. Damen J, Banwat E, Egah D, Allanana J. Parasitic contamination of vegetables in Jos, Nigeria. Ann Afr Med. 2007;6(3):115. doi:10.4103/ 15963519.55723

28. Alli J, Abolade G, Kolade A, et al. Prevalence of intestinal parasites on fruits available in Ibadan markets, Oyo State, Nigeria. Acta Parasitol Globalis. 2011;2(1):6-10.

29. Etewa S, Abdel-Rahman S, Fathy G, Abo El-Maaty D, Sarhan M. Parasitic contamination of commonly consumed fresh vegetables and fruits in some rural areas of Sharkyia Governorate, Egypt. Afro-Egypt J Infect Endem Dis. 2017;7(4):192-202. doi:10.21608/aeji.2017.17804

30. Bekele F, Shumbej T. Fruit and vegetable contamination with medically important helminths and protozoans in Tarcha town, Dawuro zone, South West Ethiopia. Res Rep Trop Med. 2019;10:19-23. doi:10.2147/RRTM.S205250

31. Punsawad C, Phasuk N, Thongtup K, Nagavirochana S, Viriyavejakul P. Prevalence of parasitic contamination of raw vegetables in Nakhon Si Thammarat province, southern Thailand. BMC Public Health. 2019;19(1):34. doi:10.1186/s12889-018-6358-9

32. Al-Sanabani A, Algalil F, Radman B, Al-Manusori R. Prevalence of intestinal parasites in fresh leafy vegetables in some farms at Dhamar city, Yemen. Int J Med Res. 2016;1(5):7-13.

33. Luz J, Barbosa M, Carvalho A, Resende S, Dias J, Martins H. Contamination by intestinal parasites in vegetables marketed in an area of Jequitinhonha Valley, Minas Gerais, Brazil. Revista de Nutriçao. 2017;30(1):127-136. doi:10.1590/1678-98652017000100012

34. Ahmed K, Nur D, Desale A, Zemat M. Parasitic contamination of freshly consumed vegetables sold in the markets and farm fields within and around Asmara. Pharmacol Online. 2018;3:19-30.

35. Dankwa K, Siaw D, Obboh E, Singh B, Nuvor S. Parasitic profile of fresh vegetables sold in selected markets of the Cape Coast Metropolis in Ghana. Annu Res Rev Biol. 2018;28(6):1-7. doi:10.9734/ARRB

36. Hailemeskel E, Kiros G, Matebe T. Parasitological contamination of fresh vegetables and its prevalence in Dessie Town, Northeast Ethiopia. J Biol Agri Healthc. 2018;8(17). Available from: https:// www.researchgate.net/publication/328804395. Accessed March 10, 2020.

37. Kudah C, Sovoe S, Baiden F. Parasitic contamination of commonly consumed vegetables in two markets in Ghana. Ghana Med J. 2018;52(2):88-93. doi:10.4314/gmj.v52i2.5

38. Said D. Detection of parasites in commonly consumed raw vegetables. Alexandria J Med. 2012;48(4):345-352. doi:10.1016/j. ajme.2012.05.005

39. Mukhtar I Role of vegetables in the transmission of intestinal parasites in Khartoum Central Market [Doctoral dissertation, Sudan University of Science \& Technology]; 2016; 3(11). Available at: http://repository.sustech.edu/handle/123456789/13365. Accessed August 20, 2019.

40. Maikai B, Baba-Onoja E, Elisha I. Contamination of raw vegetables with Cryptosporidium oocysts in markets within Zaria metropolis, Kaduna State, Nigeria. Food Control. 2013;31(1):45-48. doi:10.10 16/j.foodcont.2012.09.032

41. Nasiru M, Auta T, Bawa J. Geohelminth contamination of fruits and vegetables cultivated on land irrigated with waste water in Gusau Local Government Area, Zamfara State, Nigeria. Zoo. 2015;13:7-10.

42. Tomas Z, Kidane D. Parasitological contamination of wastewater irrigated and raw manure fertilized vegetables in Mekelle city and its suburb, Tigray, Ethiopia. Momona Ethiop J Sci. 2012;4(1):77-89. doi: $10.4314 /$ mejs.v4i1.74058

43. Mohamed M, Siddig E, Elaagip A, Edris A, Nasr A. Parasitic contamination of fresh vegetables sold at central markets in Khartoum state, Sudan. Ann Clin Microbiol Antimicrob. 2016;15(1):17. doi:10.1186/s12941-016-0133-5

44. Shehu M, Amina R. Helminths contaminants of fruits and vegetables sold in rural areas of Zamfara States, Nigeria. J Zoo Biosci Res. 2014;1(1):15-19. 


\section{Publish your work in this journal}

Research and Reports in Tropical Medicine is an international, peerreviewed, open access journal publishing original research, case reports, editorials, reviews and commentaries on all areas of tropical medicine, including: Diseases and medicine in tropical regions; Entomology; Epidemiology; Health economics issues; Infectious disease; Laboratory science and new technology in tropical medicine;

Submit your manuscript here: http://www.dovepress.com/research-and-reports-in-tropical-medicine-journal
Parasitology; Public health medicine/health care policy in tropical regions; and Microbiology. The manuscript management system is completely online and includes a very quick and fair peer-review system. Visit http://www.dovepress.com/testimonials.php to read real quotes from published authors. 